\title{
Utilization of sulphidic mine tailings in alkali-activated materials
}

\author{
Jenni Kiventerä ${ }^{1}$, Juho Yliniemi $^{1}$, Lukasz Golek $^{2}$, Jan Deja $^{3}$, Victor Ferreira ${ }^{3}$, Mirja Illikainen ${ }^{1}$ \\ ${ }^{1}$ Fibre and Particle Engineering, Univeristy of Oulu, PO Box 4300, FIN-90014Finland \\ ${ }^{2}$ Faculty of Materials Science and Ceramics / wimic, AGH University of Science and Technology 30-059 Krakow, Poland \\ ${ }^{3}$ Dept. Civil Engineering/CICECO, University of Aveiro, 3810-193 Aveiro, Portugal
}

\begin{abstract}
Disposal of mine tailings is one of the most important environmental issues during the mining lifetime. Especially sulphidic tailings can cause environmental and ecological risks because of their tendency to oxidize in the presence of water or air. Because of small particle size and harmful chemical properties, utilization possibilities of sulphidic mine tailings are limited. The aim of the present study was to develop technologies to utilize sulphidic mine tailings in alkali activated materials. Alkali-activated materials also known as geopolymers are nanosized zeolite type or slightly amorphous materials comparable to traditional Portland cement concrete, which can physically encapsulate or chemically stabilize the hazardous elements such as heavy metals into the 3D structure. Mine tailing based geopolymer aggregates were successfully produced from sulphidic mine tailings with good physical properties. The geopolymer aggregates performed as a concrete aggregate comparable to commercial lightweight aggregates. In addition, geopolymer mortars were prepared from mine tailings. In mortar application, there is a need to add some co-binder such as blast furnace slag in order to achieve high strength for the material. The mine tailing based geopolymer structure has an ability to stabilize a large number of cationic species into the structure while some anionic species were not able to immobilize by alkaline activation.
\end{abstract}

\section{Introduction}

Disposal of mine tailings is one of the most important environmental issues during the lifetime of a mine. In the $\mathrm{EU}$, mining and quarrying are contributing 727 million tons waste, which is $28.3 \%$ of the total waste amount [1]. Some of these wastes, such as sulphidic mine tailings, consist of many harmful components which can cause several environmental and ecological risks because of their tendency to oxidize in the presence of water or air. Usually, these uneconomic residues are disposed into the impounding lakes with high water content. Sulphidic tailings can oxidize which causes dissolution of metals and metalloids into water and production of sulphuric acid (H2SO4), which lowers the $\mathrm{pH}$ and thus results in leaching of heavy metals such as Cd or As [2].

The target of this research was to utilize mine tailings as a raw material in alkali activation (also known as geopolymerization). Alkali activation of hazardous waste materials can represent one of the environmentally friendly and low-cost treatment methods for the encapsulation of hazardous elements [3-5]. The alkaline solution dissolves the reactive portion of aluminosilicate powdered material and releases aluminum and silicon tetrahedral units into the solution. In following few hours the $\mathrm{Al}$ and $\mathrm{Si}$ ions are linked together by sharing all the oxygen atoms together yielding new three-dimensional amorphous matrix and loss of water [6]. The geopolymer structure can have many excellent properties such as high strength, low density, micro- or nano-porosity, low shrinkage, high thermal stability, and high chemical and fire resistance [7].
There occurs a negative charge inside the geopolymer structure which needs to be balanced by sufficient cations coming from alkaline solution or by cations coming from waste [8]. Heavy metals can be stabilized by different methods. They can be entrapped physically inside the 3D matrix produced which is called physical stabilization method. On the other hand, the heavy metal particles can be stabilized by the chemical method where the components can be bonded inside the structure as charge-balancing role as above described or they can be adsorbed onto the geopolymer structure by chemical method [8].

The aim of this work was to evaluate the possibility to utilize gold mine tailings as a raw material in alkaliactivated materials. The mechanical properties and the immobilization efficiency of the various elements in gold-mine-tailing-based geopolymers were evaluated. Metakaolin (MK), which is highly reactive aluminosilicate raw material, was used as a co-binder, together with amorphous, ground granulated blast furnace slag (GBFS), to optimize the chemical composition of the samples.

\section{Experimental}

Finnish gold mine tailings, received from a mining site in Northern Finland, were used as a raw material in these experiments. Mine tailings consist mainly of $\mathrm{SiO} 2$, $\mathrm{Al} 2 \mathrm{O} 3$, and $\mathrm{CaO}$ (Table 1) being theoretically suitable raw material for geopolymerisation. In addition, some iron oxide was seen - about $10 \%$. The content of

\footnotetext{
Corresponding author: jenni.kiventera@,oulu.fi
} 
sulphur as $\mathrm{SO} 3$ was $5.2 \%$. Iron and sulphur originate from arsenopyrite and pyrite minerals which are the main minerals mined in this particular gold mine. This was also confirmed by the ICP-OES-analysis which shows the high content of sulphur and arsenic.

Table 1. Chemical composition of mine tailings.

\begin{tabular}{c|c|c|c}
$\begin{array}{c}\text { Component } \\
(\mathbf{\%})\end{array}$ & MT & GBFS & MK \\
\hline $\mathrm{SiO}_{2}$ & 49.9 & 32.3 & 58.9 \\
\hline $\mathrm{Al}_{2} \mathrm{O}_{3}$ & 10.4 & 9.6 & 34.7 \\
\hline $\mathrm{Fe}_{2} \mathrm{O}_{3}$ & 9.7 & 1.2 & 1.4 \\
\hline $\mathrm{CaO}$ & 11.1 & 38.5 & 0.1 \\
\hline $\mathrm{MgO}$ & 5.9 & 10.2 & 0.1 \\
\hline $\mathrm{SO}_{3}$ & 5.2 & & \\
\hline $\mathrm{Na}_{2} \mathrm{O}$ & 3.0 & 0.5 & 0.1 \\
\hline $\mathrm{K}_{2} \mathrm{O}$ & 1.3 & 0.5 & 0.7 \\
\hline $\mathrm{TiO}$ & 1.3 & 2.2 & 1.3 \\
\hline $\mathrm{S}(\mathrm{mg} / \mathrm{kg})$ & 18900 & & \\
\hline $\mathrm{As}(\mathrm{mg} / \mathrm{kg})$ & 1520.0 & & \\
\hline
\end{tabular}

Mine tailings include also high quantity of $\mathrm{Cu}, \mathrm{Cr}, \mathrm{Ni}$, $\mathrm{Zn}, \mathrm{Co}, \mathrm{Sb}$ and $\mathrm{V}$ which makes it hazardous and complicated to utilize further (Table 2). In order to improve the utilization properties of the material there need to be effective immobilization of these hazardous elements.

Table 2. The amount of minor elements in gold mine tailings.

\begin{tabular}{c|c|c|c} 
Component & MT & \multicolumn{1}{c}{ GBFS } & MK \\
\hline $\mathbf{C r}(\mathbf{m g} / \mathbf{k g})$ & 74.0 & 32.3 & 58.9 \\
\hline $\mathbf{C u}(\mathbf{m g} / \mathbf{k g})$ & 120.0 & 9.6 & 34.7 \\
\hline $\mathbf{N i}(\mathbf{m g} / \mathbf{k g})$ & 100.0 & 1.2 & 1.4 \\
\hline $\mathbf{Z n}(\mathbf{m g} / \mathbf{k g})$ & 71.0 & 38.5 & 0.1 \\
\hline $\mathbf{C o}(\mathbf{m g} / \mathbf{k g})$ & 22.0 & 10.2 & 0.1 \\
\hline $\mathbf{S b}(\mathbf{m g} / \mathbf{k g})$ & 32.0 & 0.5 & 0.1 \\
\hline $\mathbf{V}(\mathbf{m g} / \mathbf{k g})$ & 59.0 & 0.5 & 0.7 \\
\hline $\mathbf{B a}(\mathbf{m g} / \mathbf{k g})$ & 29 & 2.2 & 1.3 \\
\hline
\end{tabular}

Ground granulated blast furnace slag (GBFS) produced by Finnsementti and commercial metakaolin were used as a co-binders in these experiments. The chemical composition of these materials can be found from table 1 .

Geopolymers were prepared by adding the alkaline solution $(\mathrm{NaOH} / \mathrm{NaSil})$ into the powder precursor and were mixed until the homogeneous paste was achieved [9]. The paste produced were moulded into the plastic cylinder moulds with diameter of $25 \mathrm{~mm}$ and were allowed to cure for $28 \mathrm{~d}$ in humic air at room temperature before analysing further. Three samples of each recipes were prepared and the average of the results were calculated.

The alkali activated aggregates were produced by following steps [10]: 1) dry raw materials were weighed, mixed, and added to the drum; (2) the impeller and drum were switched on, and approximately $15 \mathrm{~g}$ of sodium silicate solution was added to prevent dusting; and (3) sodium silicate was added by the drop until the desired aggregate size (2-10 $\mathrm{mm}$ in diameter) was achieved. Each aggregate batch was sealed in airtight plastic bags and stored in ambient conditions for 28 days. Mortar and concrete samples with aggregates were prepared by mixing water, cement and sand together three minutes. The aggregates and some extra water were added and mixed three more minutes all together. The sodium silicate solution used for granulation was Zeopol 25 (Huber), which has a $\mathrm{SiO} 2 / \mathrm{Na} 2 \mathrm{O}-$ molar ratio of 2.5 and a water content of approximately $66 \mathrm{wt} \%$.

\section{Results and discussion}

\subsection{Mechanical properties of geopolymers}

The compressive strength of the specimens produced were analysed after $28 \mathrm{~d}$ of curing. Three samples of each recipe were prepared and the average of the results are shown in Fig. 1. The mine tailing based materials had only 2-4 $\mathrm{MPa}$ of strength after $28 \mathrm{~d}$. Even though the samples were hardened a bit, they were fully broken during the $24 \mathrm{~h}$ of immersion in water [9]. When using blast furnace slag as a co-binder the strength of the samples were increased. With higher slag content the higher strength were obtained (Fig. 1). It confirms that mine tailing need some co-binder in order to be used as a raw material in alkali activation. With higher concentration of $\mathrm{NaOH}$ solution the strength of the samples were also improved. Even though the strength were higher the workability decreased with the higher concentration of alkaline solution.

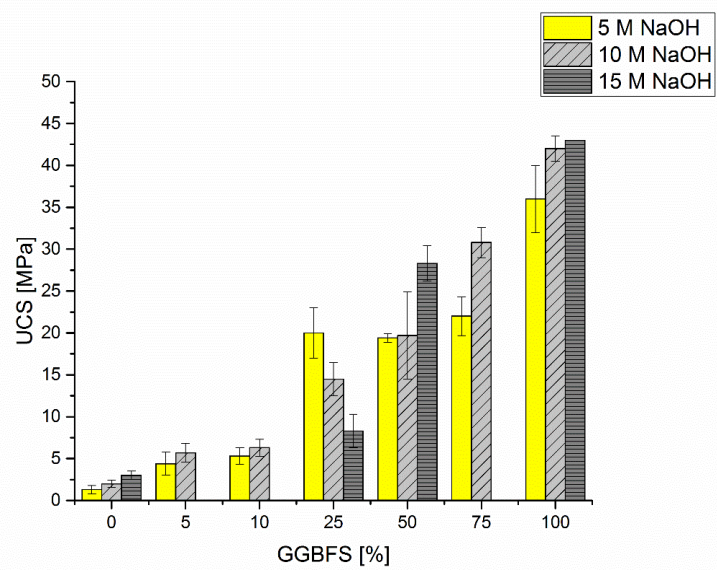

Fig. 1. UCS of bricks with different GGBFS content and $\mathrm{NaOH}$ - concentration after 28 curing days in laboratory conditions.

\subsection{Mechanical properties of aggregates}

Mine tailing based lightweight aggregates had lower mechanical strength compared to commercial lightweight aggregate (LECA) made from expanded clay 
minerals. This indicates the previous observations that mine tailing have poor reactivity properties and need some co-binder in order to be able to utilize effectively. Mortar and concrete prepared with alkali activated aggregates had instead higher mechanical strength (Figure 2), a higher dynamic modulus of elasticity, and higher density than concrete produced with LECAs, while the rheology and workability was the same.

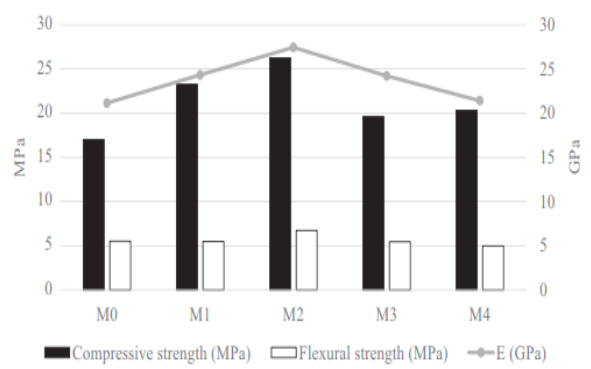

Fig. 2. Mecahnical properties of concretes made with lightweight aggregates. (M0 is for commercial aggregates LECA, M3 and M4 are MT based aggregates).

\subsection{Heavy metals stabilisation}

Due to the fact that the Si/Al molar ratio affects the physical properties of the geopolymer matrix and its inertization capacity, all the formulation for environmental analysis were designed according to geopolymer matrix with a $\mathrm{Si} / \mathrm{Al}$ ratio of $1.5-2.5$ and a $\mathrm{Na} / \mathrm{Al}$ ratio of $1.0-1.29$. By optimizing the $\mathrm{Si} / \mathrm{Al}$ and $\mathrm{Na} / \mathrm{Al}$ molar ratio to the certain level metakaolin with a

\begin{tabular}{ccccc}
\hline MT_GBFS_MK & $\begin{array}{c}\mathrm{NaOH} \\
(\mathrm{ml})\end{array}$ & $\begin{array}{c}\mathrm{Na} \\
\text { sil } \\
(\mathrm{ml})\end{array}$ & $\mathrm{Si} / \mathrm{Al}$ & $\mathrm{Na} / \mathrm{Al}$ \\
\hline 50_50_0 & $30(8 \mathrm{M})$ & 0 & 3,5 & 1,5 \\
50_20_30_(8MNaOH$)$ & $20(8 \mathrm{M})$ & 25 & 2,6 & 0,9 \\
40_30_30_(8MNaOH) & $20(8 \mathrm{M})$ & 25 & 2,5 & 0,8 \\
50_20_30_(9MNaOH) & $20(9 \mathrm{M})$ & 25 & 2,6 & 0,9 \\
40_30_30_(9MNaOH) & $20(9 \mathrm{M})$ & 25 & 2,5 & 0,9 \\
\hline
\end{tabular}

$\mathrm{Si} / \mathrm{Al}$ mass ratio of 1.7 was used to adjust the $\mathrm{Al}$ content, Al being scarce in the other two precursors (Table 3).

Table 3. Geopolymer formulations for environmental analysis.

The immobilization efficiency of the prepared samples is shown in Figure 3. The leachable amounts of $\mathrm{Be}, \mathrm{Co}, \mathrm{Hg}, \mathrm{Pb}$, and $\mathrm{Ti}$ were very low before and after alkali activation. Also, the leaching amounts of $\mathrm{Cr}, \mathrm{Cu}$, $\mathrm{Zn}$, and $\mathrm{Ni}$ were low. Longer curing period slightly improved the immobilization of these elements. The immobilization efficiency of $\mathrm{Cr}, \mathrm{Cu}, \mathrm{Zn}, \mathrm{Ni}$, and $\mathrm{Mn}$ were higher than $98 \%$ meaning that there is a possibility to stabilize huge amounts of different cationic elements by alkali activation.
The leachability of the As and V were high after the geopolymerization. This is because of these elements can form oxyanions in high alkaline conditions having high mobility [10]. They cannot precipitate in high alkaline conditions and they do not have any certain place in the geopolymer structure either. The chemical composition of the specimens produced did not improved the immobilisation efficiency of these elements. Instead the longer curing period decreased the leaching of these components. Although the leachable amounts of these oxyanions were high there were still possibility to immobilize more than $80 \mathrm{wt} \%$ of those elements from the starting materials by alkali activation which is encouraging results for waste materials with lower amount of these elements.

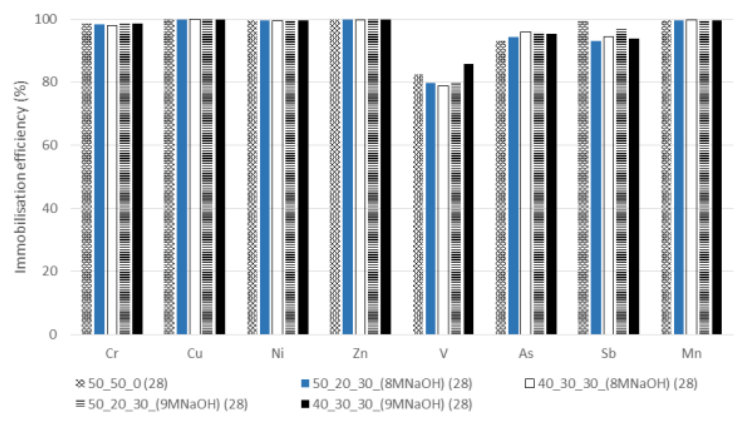

Fig. 3. Immobilization efficiency of heavy metal components.

\section{Conclusion}

Gold mine tailings were able to be used as a raw material in alkali-activated materials with a proper co-binder material such as blast furnace slag or metakaolin. The strength of the samples was increased with higher slag content in the mixture and the higher alkaline concentration of the alkaline solution increased the strength. Also, the mine tailings were able to be utilized as a raw material in lightweight aggregates. The mechanical properties were higher than commercial aggregates (LECAs) have when MT based aggregates were used in mortar and concrete samples.

According to environmental analysis, there is a possibility to stabilize a large number of cationic species into the alkali-activated structure. The most problematic elements were sulphates and oxyanions which had high mobility in alkaline conditions. The longer curing period improved the immobilization efficiency and more than $98 \%$ of all oxyanions were able to be immobilized into the structure. The long-term durability of the material should be evaluated carefully and the immobilisation mechanism should be evaluated in the future more detailed.

References

1. http://epp.eurostat.ec.europa.eu/statistics_explained/ index.php/Waste_statistics 
2. Ahmari, S. \& Zhang, L. 2013. Construction and Building Materials, 44, 743-750

3. Diaz-Loya, I., Allouche E., Eklund, S., Joshi. A., Kupwade-Patil. K. 2010. Waste Management, 32, $1521-1527$

4. Lancellotti, I., Kamseu, E., Michelazzi, M., Barbieri, L., Corradi, A., Leonelli, C., 2010. Waste Management, 30, 673-679.

5. Zheng, L., Wang, W., Gao, X., 2016. Waste Manag. 58, 270-279.

6. Komnitsas, K., Zaharaki, D., 2007. Miner. Eng. 20, 1261-1277.

7. Davidovits, J., 1991. J. Therm. Anal. 37, 16331656.

8. Van Jaarsveld, J.G.S., Van Deventer, J.S.J., Lorenzen, L., 1997. Miner. Eng. 10, 659-669.

9. Kiventerä, J., Golek, L., Yliniemi, J., Ferreira, V., Deja, J., Illikainen, M., 2016. Int. J. Miner. Process. 149, 104-110.

10. Yliniemi, J., Paiva, H., Ferreira, V., Tiainen M., Illikainen M., 2017. Construction and Building Materials, 131, Pages 784-792

11. Fawcett, S.E., Jamieson, H.E., Nordstrom, D.K., McCleskey, R.B., 2015. Appl. Geochem. 62, 3-17. 